\title{
Enhanced Expression of Interferon Regulatory Factor-1 in the Mucosa of Children with Celiac Disease
}

\author{
VIRGINIA M. SALVATI, THOMAS T. MACDONALD, GIOVANNA DEL VECCHIO BLANCO, \\ GIUSEPPE MAZZARELLA, IVAN MONTELEONE, PIERO VAVASSORI, \\ SALVATORE AURICCHIO, FRANCESCO PALLONE, RICCARDO TRONCONE, AND \\ GIOVANNI MONTELEONE
}

\begin{abstract}
Department of Pediatrics and European Laboratory for the Investigation of Food-Induced Diseases, University Federico II, Naples, Italy [V.M.S., S.A., R.T.], Division of Infection, Inflammation and Repair, University of Southampton, School of Medicine, Southampton General Hospital, Southampton, U.K. [T.T.M.], Dipartimento di Medicina Interna, Università Tor Vergata, 00133 Rome, Italy [G.D.V.B., I.M. P.M., F.P., G.Mo.], Istituto di Scienze dell'Alimentazione, CNR, Avellino, Italia [G.Ma]
\end{abstract}

\begin{abstract}
Celiac disease $(C D)$ is an enteropathy characterized by a Th1-type immune response to the dietary gluten. The transcriptional mechanisms or factors that control Th1 cell development in this condition remain to be elucidated. The aim of this study was to analyze in $\mathrm{CD}$ the expression of interferon (IFN) regulatory factor (IRF)-1, a transcription factor that regulates the differentiation and function of Th1 cells. Duodenal biopsies were taken from children with untreated CD and control children, and analyzed for IRF-1 by Southern blotting of reverse-transcriptase PCR products and Western blotting. IRF-1 DNA-binding activity was assessed by electrophoretic shift mobility assay. The effect of gliadin stimulation on IRF-1 induction was investigated in an ex vivo organ culture of treated CD biopsies. Enhanced IRF-1 was seen in untreated CD in comparison with controls. This was evident at both the RNA and protein level. Furthermore, untreated CD samples exhibited stronger nuclear accumulation and DNA-binding activity of IRF-1 than controls. In contrast, IRF-2, a transcriptional repressor that binds the same DNA element and competes with IRF-1, was expressed at the same level in nuclear proteins extracted from both untreated $\mathrm{CD}$ and control patients.
\end{abstract}

\section{ABSTRACT}

In explant cultures of treated CD biopsies, gliadin enhanced both IRF-1 RNA and protein. This effect was prevented by a neutralizing IFN- $\gamma$ antibody. Furthermore, stimulation of normal duodenal biopsies with IFN- $\gamma$ enhanced IRF-1. These data indicate that IRF-1 is a hallmark of the gliadin-mediated inflammation in $\mathrm{CD}$ and suggest that IFN- $\gamma /$ IRF-1 signaling pathway can play a key role in maintaining and expanding the local Th1 inflammatory response in this disease. (Pediatr Res 54: 312-318, 2003)

\section{Abbreviations}

CD, celiac disease

IRF-1, interferon regulatory factor-1

STAT1, signal transducer and activator of transcription 1

Th1, T-helper cell type 1

IFN, interferon

IEL, intraepithelial lymphocytes

EC, epithelial cells

LPMC, lamina propria mononuclear cell

ECL, enhanced chemiluminescence
$\mathrm{CD}$ is a gluten-mediated enteropathy of the proximal small intestine characterized by villous atrophy, crypt cell hyperplasia, and increased number of IEL (1). Accumulating evidence

Received July 31, 2002; accepted January 16, 2003.

Correspondence: Giovanni Monteleone, Cattedra di Gastroenterologia, Dipartimento di Medicina Interna, Università Tor Vergata, Via Montpellier, 1, 00133 Rome, Italy; e-mail: Gi.Monteleone@Med.uniroma2.it

Supported by a European Union grant (ERBFMRXCT9) and the Commission of the European Communities specific program, "Quality of Life and Management of Living Resources," QLRT-CT 1999-00037, "Evaluation of the Prevalence of Coeliac Disease and its Genetic Components in the European Population."

This article does not necessarily reflect the views of the Commission of the European Communities and in no way anticipates the Commission's future policy in this area.

DOI: 10.1203/01.PDR.0000079184.70237.9C indicates that $\mathrm{CD} 4+\mathrm{T}$-cell-mediated hypersensitivity plays a major role in tissue injury in $\mathrm{CD}$. Lamina propria CD4+ T cells are phenotypically activated and produce large amounts of Th1 cytokines in response to gluten stimulation $(2,3)$. Functional studies have demonstrated that activation of lamina propria Th1 cells can modulate extracellular matrix deposition and epithelial proliferation $(4,5)$. Enhanced synthesis of Th2 cytokines, such as IL-4, has also been reported in some studies (6).

Polarization of Th cells along the Th1 or Th2 pathway is influenced by a number of factors, such as the nature and concentration of the antigen, the type of antigen-presenting cells, and the microenvironment at the time of antigen expo- 
sure (7). In addition, evidence has accumulated to show that distinct cytokine signaling and specific transcription factors are crucial in controlling commitment to a Th1 or Th2 phenotype (8).

The factors responsible for the Th1 response in $\mathrm{CD}$ are not known. We have recently demonstrated that IFN- $\alpha$, a cytokine produced by virally infected cells that can promote IFN- $\gamma$ synthesis and Th1 cell differentiation in humans, is produced in excess in CD (9). We have also provided evidence that activation of lamina propria $T$ cells in the fetal gut model with anti-CD3 and IFN- $\alpha$ stimulates Th1 cytokine production and crypt cell hyperplasia, indicating a role for IFN- $\alpha$ in the pathogenesis of CD (10). Furthermore, in CD but not in normal duodenal mucosa, there is production of active IL-18, which is able to enhance Th1-cell polarization (11). Finally, it has recently been proposed that IL-15, a cytokine that is able to expand Th1-cell differentiation under particular conditions, may be involved in the CD immune response $(12,13)$. However, the transcriptional mechanisms that underlie the distinct Th1-type cytokine repertoire in CD remain unknown.

IRF-1 is a member of a family of transcription factors that share structural similarity in their DNA-binding domain and binding specificity (14). IRF-1 RNA is expressed in a variety of cell types, and its expression is dramatically up-regulated after viral infection or IFN stimulation $(14,15)$. IRF-1 was originally identified as a protein binding to the virus-inducible enhancer of the human IFN- $\alpha / \beta$ genes (15). Initial studies using a cDNA overexpression system revealed that high-level expression of IRF-1 was sufficient to induce IFN- $\alpha / \beta$ in the absence of virus infection, indicating that IRF-1 functions as a transcriptional activator of IFN- $\alpha / \beta$ genes (16). More recently, studies in knockout mice have shown that lack of IRF-1 results in an impaired release of IL-18, defective synthesis of IL-15 and IFN- $\gamma$, and enhanced production of Th2 cytokines (17-19). Taken together, these observations reveal a critical role for IRF-1 in the Th1-cell differentiation programs.

\section{METHODS}

Patients and controls. Three or more biopsy specimens from the distal duodenum of 18 children with untreated $\mathrm{CD}$ (median age, $11 \mathrm{y}$; range, 6-16 y) were obtained during upper gastrointestinal endoscopy. One specimen was used for routine histologic examination, whereas the remaining were immediately frozen in liquid nitrogen and stored until tested. The histopathologic diagnosis was based on typical mucosal lesions with crypt cell hyperplasia, villous atrophy, and increased number of IEL. All CD patients were positive for antiendomysial (EMA) and anti-gliadin (AGA) antibodies. Duodenal biopsies were also collected from seven children with treated CD (median age, 13 y: range, 10-15 y), undergoing upper endoscopy for recurrent abdominal pain. All treated CD patients had normal histology and were AGA and EMA negative. Age-matched control patients $(n=14$; median age, $14 \mathrm{y}$; range, 13-16 y) were under investigation for gastrointestinal symptoms, but had normal histology and were EMA and AGA negative. This study received ethical approval from the local committee (University Federico II, Naples, Italy). Informed consent was obtained from parents of all children enrolled.

Organ culture and cell isolation. The mucosal specimens were cultured as described elsewhere (20). Briefly, biopsies were placed on iron grids with the mucosal face upward in the central well of an organ culture dish in culture medium containing RPMI 1640 (Sigma-Aldrich SRL, Milan, Italy) supplemented with 10\% HL-1 (BioWhittaker, Wokingham, U.K.), penicillin $(100 \mathrm{U} / \mathrm{mL})$ and streptomycin $(100 \mu \mathrm{g} / \mathrm{mL})$ (Invitrogen Italia SRL, San Giuliano Milanese, Italy). Cultures were performed with or without the addition of $1 \mathrm{mg} / \mathrm{mL}$ peptictryptic digest of gliadin (PT) (Sigma-Aldrich SRL) for 8 and $24 \mathrm{~h}$ in the presence or absence of a neutralizing IFN- $\gamma$ or isotype control antibody $(5 \mu \mathrm{g} / \mathrm{mL}$ final concentration; R\&D Systems, Minneapolis, MN, U.S.A.). Furthermore, normal duodenal biopsies were stimulated with recombinant human IFN- $\gamma(30 \mathrm{ng} / \mathrm{mL}$; Peprotech EC Ltd., London, U.K.) for $24 \mathrm{~h}$. The dishes were placed in a tight container with $95 \% \mathrm{O}_{2} / 5 \%$ $\mathrm{CO}_{2}$ at $37^{\circ} \mathrm{C}$, at 1 bar. At the end of the culture, biopsies were snap-frozen and stored at $-80^{\circ} \mathrm{C}$ until used. EC and LPMC were isolated from duodenal biopsies taken from three active CD patients and three normal controls by the DTT-EDTAcollagenase procedure (21) and used for protein extraction. An aliquot of EC was also used for excluding the presence of LPMC contaminating the EC samples as described elsewhere (22).

Protein extraction and Western blot analysis. Western blot analysis was performed on whole mucosal duodenal samples from eight active $\mathrm{CD}$ children and eight control children. For cytosolic and nuclear extracts, the method described by Schreiber et al. (23) was used with minor modifications. Briefly, snap-frozen biopsies were mechanically homogenized in liquid nitrogen, and cytosolic extracts collected in buffer A containing $10 \mathrm{mM}$ HEPES (pH 7.9), $10 \mathrm{mM} \mathrm{KCl}, 0.1 \mathrm{mM}$ EDTA, and 0.2 mM EGTA. Nuclear extracts were prepared by solubilizing the remaining nuclei in buffer $\mathrm{C}$ containing $20 \mathrm{mM}$ HEPES $(\mathrm{pH}$ 7.9), $0.4 \mathrm{M} \mathrm{NaCl}, 1 \mathrm{mM}$ EDTA, $1 \mathrm{mM}$ EGTA, and $10 \%$ glycerol. Both buffers were supplemented with $1 \mathrm{mM}$ DTT, 10 $\mu \mathrm{g} / \mathrm{mL}$ aprotinin, $10 \mu \mathrm{g} / \mathrm{mL}$ leupeptin, and $1 \mathrm{mM}$ phenylmethanesulphonyl fluoride (all reagents were from Sigma-Aldrich SRL).

For the detection of IRF-1, cytosolic proteins (150-250 $\mu \mathrm{g} / \mathrm{sample}$ ) were separated on a $10 \%$ SDS-PAGE gel. IRF-1 was detected using a polyclonal rabbit anti-human IRF-1 antibody (1:300 final dilution) (Santa Cruz Biotechnology, Santa Cruz, CA, U.S.A.) followed by a horseradish peroxidaseconjugated goat anti-rabbit IgG MAb (DAKO, Carpinteria, CA, U.S.A.) (final dilution 1:2500). The reaction was detected with ECL Plus kit (Amersham Pharmacia Biotech U.K. Ltd., Little Chalfont, Buckinghamshire, U.K.). To confirm equal loading and transfer of proteins, ponceau S (Sigma-Aldrich SRL) staining was performed. Computer-assisted scanning densitometry was used to analyze the intensity of the immunereactive bands in the autographs.

To analyze the content of IRF-1 in the nuclear extracts, 10 $\mu \mathrm{g}$ of nuclear protein/sample were separated on a $10 \% \mathrm{SDS} /$ PAGE gel and analyzed using the polyclonal human IRF-1 antibody as indicated above. After detection of IRF-1, blots 
were stripped by and subsequently incubated with a mouse anti-human histone-1 MAb (1:300 final dilution, Santa Cruz Biotechnology) followed by a goat anti-mouse antibody conjugated to horseradish peroxidase (1:1500 final dilution, DAKO). In addition, each sample was analyzed for the content of IRF-2. For this purpose, $10 \mu \mathrm{g}$ of nuclear protein/sample were separated on a $10 \%$ SDS/PAGE gel and analyzed using the rabbit anti-human IRF-2 polyclonal antibody (1:300 final dilution, Santa Cruz Biotechnology) followed by a goat antimouse antibody conjugated to horseradish peroxidase (1:1500 final dilution, DAKO).

RNA extraction, $c D N A$ preparation, and Southern blotting of $\boldsymbol{R T}$-PCR products. RNA was extracted from biopsy specimens from eight $\mathrm{CD}$ patients and eight normal controls using $1 \mathrm{~mL}$ of a monophasic solution of phenol and guanidine isothiocyanate (TRizol, Invitrogen Italia SRL) and chloroform, followed by isopropanol (Sigma-Aldrich SRL) precipitation. The integrity of RNA was checked by electrophoresis on a $1.5 \%$ agarose gel. A constant amount of RNA (150 ng/sample) was retrotranscribed into complementary cDNA, and $1 \mu \mathrm{L}$ of cDNA/sample was then amplified using the following conditions: denaturation $1 \mathrm{~min}$ at $94^{\circ} \mathrm{C}$, annealing $1 \mathrm{~min}$ at $55^{\circ} \mathrm{C}$ for $\beta$-actin and $54^{\circ} \mathrm{C}$ for IRF-1, and extension $1 \mathrm{~min}$ and $15 \mathrm{~s}$ at $72^{\circ} \mathrm{C}$ as previously reported (24)

RNA expression for IRF-1 and $\beta$-actin was then assessed semi-quantitatively by Southern blotting. In preliminary experiments, we established the optimal number of cycles to obtain a PCR product within the linear phase of the amplification. For this purpose, an equivalent amount of cDNA for sample was amplified using specific primers for $\beta$-actin ( $1 \mu \mathrm{L}$ of cDNA for $19,21,23$, and 25 cycles $)$ and for IRF-1 ( $1 \mu \mathrm{L}$ of cDNA for 28 , 30,31 , and 33 cycles). For Southern blot experiments, cDNA samples were amplified with $\beta$-actin primers for 20 cycles and with IRF-1 for 28 cycles. The IRF-1 primers were as follows: FWD: 5'-GTGGAAGTTGTGCCGGACA-3' and REV: 5'CTTGCCTAGAGGAATAAGAGG-3'; $\beta$-actin primers have been published previously (24). Parallel experiments were carried out using RNA as substrate for PCR assay to exclude the amplification of genomic DNA contaminating the RNA samples. PCR product specificity was confirmed by restriction analysis. The cDNA probes used in the Southern blotting were DNA fragments encoding the full-length PCR product. Reverse-transcriptase (RT)-PCR products were run on a $1 \%$ agarose gel, and Southern blotting was carried out according to a commercially available chemiluminescence detection kit (Amersham Pharmacia Biotech). Intensity of the bands was measured by densitometry.

Electrophoretic mobility shift assay. Electrophoretic mobility shift assay (EMSA) was used to detect specific binding of IRF-1 to an oligonucleotide from the type IV CIITA promoter (5'-TGCAGAAAGAAAGTGAAAGGGAAAAAGAAC-3'). Nuclear protein-DNA binding studies were carried out for 20 min at room temperature in a $20 \mu \mathrm{L}$ reaction volume containing $10 \mathrm{mM}$ Tris, $50 \mathrm{mM} \mathrm{KCl}, 1 \mathrm{mM}$ DTT, $2.5 \%$ glycerol, 5 $\mathrm{mM} \mathrm{MgCl} 2,1 \mu \mathrm{g}$ Poly (dI-dC) (all the reagents were from Sigma-Aldrich SRL), $50 \mathrm{fmol}$ biotin-labeled probe, and $10 \mu \mathrm{g}$ nuclear proteins. The DNA probe was prepared by annealing the two consensus oligonucleotides, which were labeled at the $3^{\prime}$ end with biotin using a commercially available kit (Pierce Chemical, Rockford, IL, U.S.A.). The binding specificity was confirmed by incubating the nuclear protein samples with unlabelled IRF-1/CIITA probe or unlabelled nonspecific oligonucleotide (AP-1, 5'-CGCTTGATGACTCAGCCGGAA-3') in 30-fold molar excess. In antibody blocking assays, a rabbit anti-human IRF-1 (Santa Cruz Biotechnology) or control isotype IgG antibody (DAKO) (both used in the amount of 1.5 $\mu \mathrm{g} / \mathrm{mL}$ ) were incubated with the nuclear proteins. A $7 \%$ nondenaturing polyacrylamide gel was used for electrophoretic separation. After blotting to a membrane, labeled oligonucleotides were detected with a chemiluminescence EMSA kit (Pierce Chemical).

Statistical analysis. Differences between groups were compared using the nonparametric Mann-Whitney $U$ test.

\section{RESULTS}

In vivo expression of IRF-1 in CD. IRF-1 was analyzed by Western blotting using proteins extracted from duodenal mucosal samples of eight untreated CD patients and eight controls. Immunoreactivity for IRF-1 was seen in all CD patients and six of eight control samples. There was a clear increase in the intensity of the IRF-1 bands in CD compared with controls (Fig. 1A). The median IRF-1 protein was 68 densitometry arbitrary units (range, 56-89) in CD and 28 (range, 5-43) in controls (Fig. $1 B)(p=0.002)$. IRF-1 was more pronounced in both EC and LPMC samples taken from patients with active $\mathrm{CD}$ in comparison to normal controls (Fig. 1A, inset).

To analyze whether IRF-1 is regulated at the transcriptional level, mucosal samples from untreated CD patients and con-

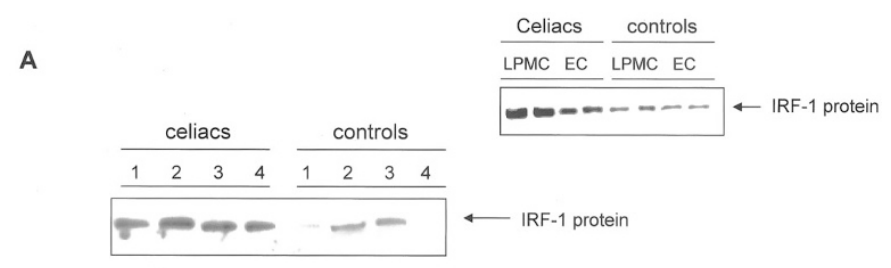

B

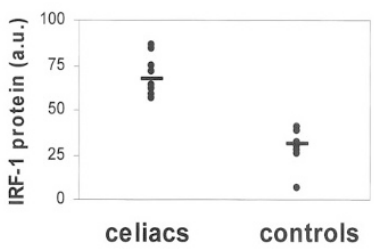

Figure 1. Enhanced IRF-1 protein in untreated CD. $(A)$ Representative expression of IRF-1 protein in mucosal samples taken from four patients with untreated CD and four normal controls. The example is representative of three separate experiments analyzing in total mucosal samples from eight patients with $\mathrm{CD}$ and eight normal controls by Western blotting. (Inset) Western blot analysis of IRF-1 in LPMC and EC isolated from duodenal biopsies from patients with untreated $\mathrm{CD}$ and normal controls. The example is representative of two separate experiments analyzing in total mucosal samples from three patients with CD and three controls. $(B)$ Quantitative analysis of IRF-1 protein in mucosal samples from eight patients with $\mathrm{CD}$ and eight normal controls, as measured by densitometry scanning of Western blots. Values are expressed in arbitrary units (a.u.). Each point represents the value (a.u.) of IRF-1 protein in mucosal samples taken from a single subject. Horizontal bars indicate the median. 
trols were also assessed for the content of IRF-1 RNA by Southern blotting of RT-PCR products. All samples from CD and controls contained transcripts for IRF-1 (Fig. 2). However, analysis of the ratio of IRF-1 and $\beta$-actin transcript bands showed a more pronounced expression of IRF-1 in CD compared with controls (Fig. $2 B$ ), thus confirming the Western blot data.

Although the arbitrary units may not directly reflect the biologic quantities of IRF-1 RNA and protein within the intestinal mucosa, the fact that in each CD sample the intensity of IRF-1 band was increased compared with that seen in controls suggests that this transcription is increased in CD.

Increased IRF-1 DNA-binding activity in CD. After its induction, IRF-1 rapidly translocates to the nucleus, where it binds to specific DNA sequences (14). Consistent with this, we found that immunoreactivity for IRF-1 was greater in nuclear extracts of duodenal biopsies from untreated $\mathrm{CD}$ patients than in controls (Fig. 3). Another IRF family member, IRF-2, binds the same DNA sites and competes with IRF-1 (25). Indeed, the level of IRF-2 within the nucleus is inversely related to the IRF-1-binding DNA activity (25). Therefore, we then analyzed the expression of IRF-2 in nuclear protein taken from untreated CD patients and controls by Western blotting. As shown in Figure 3, IRF-2 was expressed at the same level in CD and controls, although, in both groups, expression was low.

Next, we wished to determine whether in CD there is increased IRF-1 DNA-binding activity. To accomplish this,

A

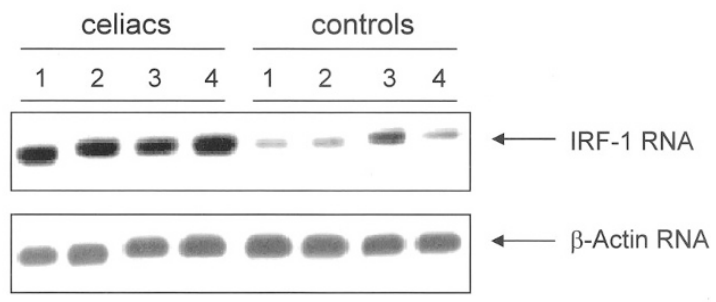

B

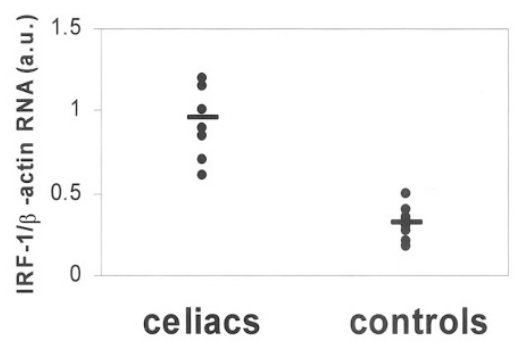

Figure 2. IRF-1 RNA transcripts in untreated CD. (A) Southern blot analysis of transcripts for IRF- 1 and $\beta$-actin in duodenal mucosal tissue homogenates from four patients with untreated $\mathrm{CD}$ and four normal controls. cDNA samples were amplified using specific primers for IRF-1 or $\beta$-actin respectively. RT-PCR products were separated on agarose gel, blotted, and hybridized with specific probes for IRF-1 or $\beta$-actin. The example is representative of three separate experiments analyzing in total mucosal samples from eight patients with CD and eight controls. $(B)$ Quantitative analysis of IRF-1/ $\beta$-actin ratio in mucosal samples from eight patients with $\mathrm{CD}$ and eight normal controls, as measured by densitometry scanning of Southern blots. Values are expressed in arbitrary units (a.u.). Each point represents the value (a.u.) of IRF-1/ $\beta$-actin ratio in mucosal samples taken from a single subject. Horizontal bars indicate the median.

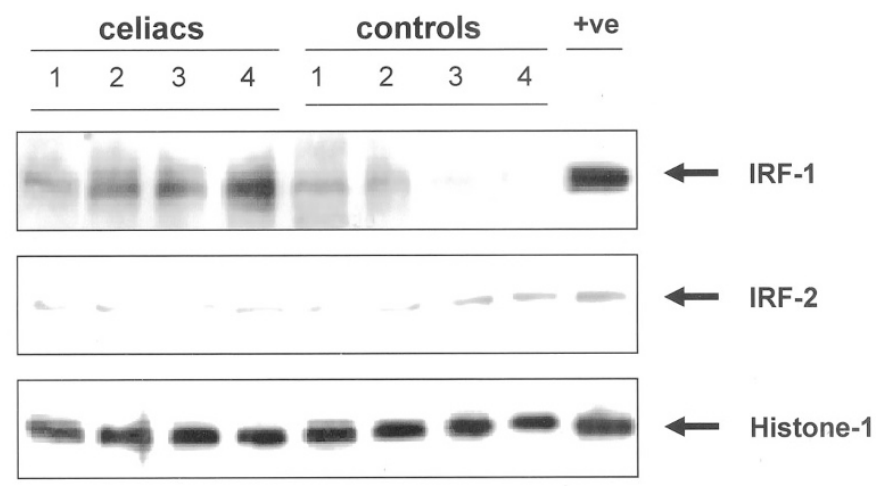

Figure 3. Enhanced nuclear accumulation of IRF-1 in untreated CD. Representative Western blot of IRF-1 (upper panel), IRF-2 (middle panel), and histone-1 (lower panel) in nuclear proteins extracted from four patients with untreated CD and four normal controls. The example is representative of three separate experiments analyzing in total mucosal samples from eight patients with $\mathrm{CD}$ and eight normal controls. +ve, THP-1 cells stimulated with recombinant human IFN- $\gamma(30 \mathrm{ng} / \mathrm{mL})$ for $4 \mathrm{~h}$

nuclear proteins were prepared from untreated CD and control biopsies, and binding to an oligonucleotide containing the IRF-1 site from the type IV CIITA promoter was assessed. As shown in Figure 4, nuclear extracts from all untreated CD and control samples formed an IRF-1 protein-DNA complex, but the intensity of this band was more pronounced in CD. The specificity of complex formation was examined by competition experiments using a 30-fold molar excess of unlabelled IRF1/CIITA probe and supershift analysis.

Enhancement by gliadin of IRF-1 expression in treated $C D$ biopsies. To show that in $\mathrm{CD}$ the gliadin-mediated immune response is related to IRF-1, we used an established ex vivo organ culture in which biopsies from treated CD patients or normal controls were stimulated with gliadin. In explants from treated CD biopsies, but not controls, stimulation with gliadin resulted in an enhanced induction of IRF-1 at both RNA and protein level (Fig. 5). Similarly, challenge of treated CD biopsies with gliadin for $24 \mathrm{~h}$ enhanced IRF-1 protein, and this effect was inhibited by a neutralizing IFN- $\gamma$ antibody (Fig. 6A). In addition, stimulation of normal duodenal biopsies with IFN- $\gamma$ increased IRF-1 protein, thus suggesting a role for this cytokine in mediating IRF-1 induction at the duodenal level (Fig. 6B).

\section{DISCUSSION}

In this study, we show for the first time that in the mucosa of patients with untreated CD there is enhanced expression of IRF-1, at both RNA and protein level, as well as increased nuclear accumulation and IRF-1 DNA-binding activity. Furthermore, we provide evidence that stimulation of treated CD biopsies with gliadin is followed by the induction of IRF-1.

The exact mechanisms responsible for the sustained increase of IRF-1 in CD remain to be elucidated. It is well documented that IRF-1 promoter contains STAT1 binding sites and that signaling via the IFN receptor promotes transcription of IRF-1 through activation of STAT1 (14). In keeping with this, IFNinduced expression of IRF-1 mRNA is completely abolished in STAT1-deficient cells (26). We have recently shown enhanced 
A
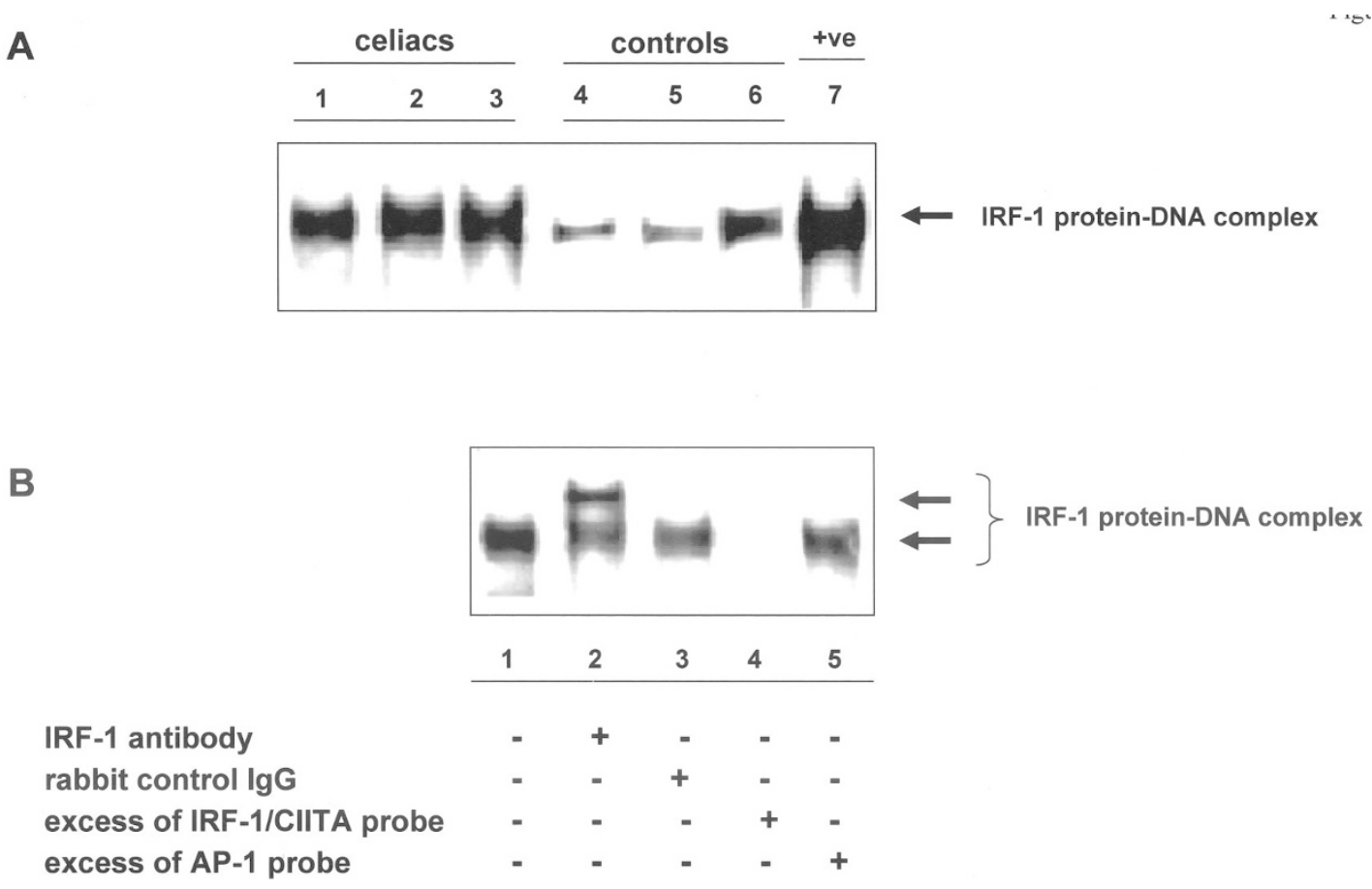
IRF-1 antibody rabbit control IgG excess of AP-1 probe

$\begin{array}{rrrrr}- & + & - & - & - \\ - & - & + & - & - \\ - & - & - & + & - \\ - & - & - & - & +\end{array}$

Figure 4. Nuclear extracts from untreated CD exhibit enhanced IRF-1 DNA-binding activity. (A) Representative EMSA blot showing enhanced IRF-1 DNA-binding activity in CD. Nuclear proteins extracted from mucosal biopsies from three patients with untreated CD (lanes 1-3) and three normal controls (lanes 4-6) were analyzed as indicated in materials and methods. IFN- $\gamma$-stimulated THP-1 cells were used as a positive control (+ve) (lane 7). One of two separate experiments analyzing samples from sevem patients with $\mathrm{CD}$ and seven controls is shown. $(B)$ Representative EMSA blot showing the specificity of the IRF-1 protein-DNA complex. Lane 1 shows the binding of nuclear proteins extracted from a mucosal biopsy of an untreated CD patient to the IRF-1/CIITA probe. Incubation of nuclear proteins, extracted from the same mucosal biopsy, with a human IRF-1 antibody (lane 2) causes a supershift of the complex, whereas with an excess of unlabelled IRF-1/CIITA probe (lane 4) causes a complete disappearance of the IRF-1 protein-DNA complex. In contrast, incubation of nuclear proteins with a nonrelevant control (IgG) antibody (lane 3) or excess of unlabelled nonspecific oligonucleotide probe AP-1 (lane 5) does not affect the IRF-1 protein-DNA complex. One of two representative experiments is shown.

activation of STAT1 and STAT1 DNA-binding activity in untreated $\mathrm{CD}$ mucosa, and also that challenge of treated $\mathrm{CD}$ biopsies with gliadin results in functionally active STAT1 (unpublished experiments). It is thus highly likely that the IFN/STAT1 signal transduction pathway contributes to enhance IRF-1 expression in CD. Indeed, the addition of a neutralizing IFN- $\gamma$ antibody to our CD biopsy cultures completely prevented the gliadin-mediated IRF-1 induction. Finally, we provide evidence that IRF-1 is induced in normal duodenal biopsies stimulated in vitro with IFN- $\gamma$. Because the IRF-1 gene is also regulated by nuclear factor- $\kappa \mathrm{B}(\mathrm{NF}-\kappa \mathrm{B})$ (26), we cannot exclude the possibility that NF- $\kappa \mathrm{B}$ is involved.

A major histologic feature of untreated $\mathrm{CD}$ is the marked infiltration of the small intestinal mucosa with both IEL and lamina propria $\mathrm{T}$ cells, which produce high levels of IFN- $\gamma$ $(1-3,27)$. How IFN- $\gamma$-secreting Th1 cells are generated in CD remains unknown. A possibility is that naive $\mathrm{T}$ cells migrate from the blood into the $\mathrm{CD}$ intestinal mucosa where they then differentiate along the Th1 pathway in response to locally produced Th1-inducing factors. It is also possible that Th1 cells primed in the Peyer's patches subsequently seed the lamina propria of $\mathrm{CD}$ patients, where locally produced factors may contribute to maintain and expand the gluten-specific Th1 response (28-30). Indeed, we have recently shown that in CD mucosa there is enhanced production of IFN- $\alpha$ and IL-18, two Th1-promoting cytokines $(9,11)$. The role of IRF-1 in CD remains to be clarified, because the number of mucosal cells we could purify from single small biopsies was not sufficient to carry out functional experiments. However, functional analysis of the role of IRF-1 in other systems has clearly shown that this transcription factor is critical in the differentiation of IFN- $\gamma$ secreting cells $(14,15,25,31)$. It is therefore conceivable that IRF-1 plays an important role in the development of the Th1 immune response in $\mathrm{CD}$, as documented in other Th1-mediated immune diseases (32-35). The molecular mechanism that underlies the ability of IRF-1 to promote Th1 cell polarization is not fully understood. It is unlikely that IRF-1 directly affects transcription of the IFN- $\gamma$ gene, because no binding sites for IRF-1 have been reported in the promoter of the IFN- $\gamma$ gene. The more plausible explanation is that IRF-1 facilitates indirectly the induction of Th1 cells by positively regulating the synthesis of Th1-inducing cytokines, including IFN- $\alpha$, IL-15, and IL-18 $(16,17)$. It would also be important to emphasize that these cytokines can, through the induction of IFN- $\gamma$, eventually enhance transcription of IRF-1 and generate a positive feedback loop able to maintain and expand the Th1 response in $\mathrm{CD}$.

In addition to its role in the regulation of Th1 cell differentiation, IRF-1 can contribute to amplify and maintain chronic inflammation and favor autoimmunity (31-34). This largely relies on the ability of IRF-1 to modulate several immuneregulatory genes (e.g. inducible nitric oxide synthase, nitric oxide, class II transactivator), as well as to facilitate the recruitment of inflammatory cells within the inflamed tissue 
A
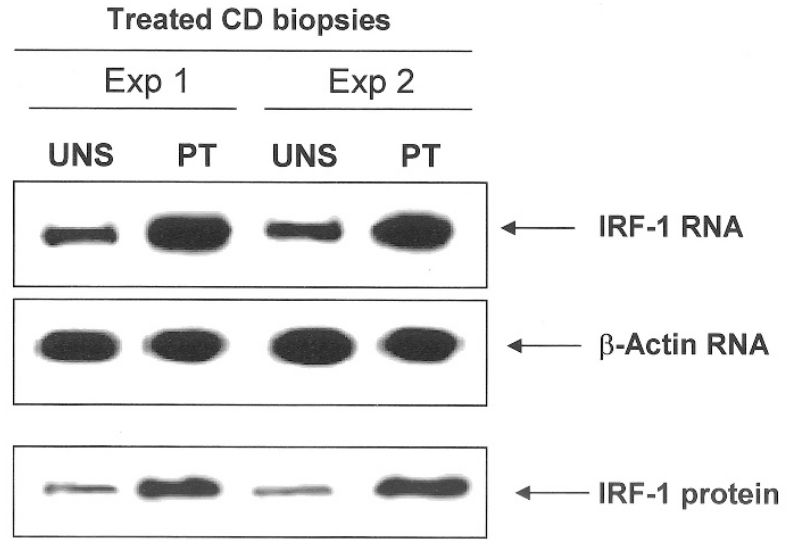

B

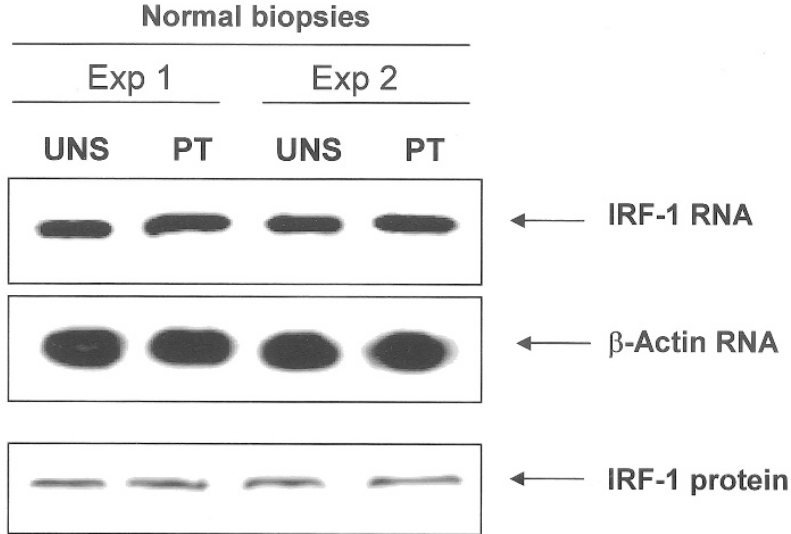

Figure 5. Stimulation of treated $\mathrm{CD}$ but not normal control biopsies with gliadin results in enhanced IRF-1 induction. (A) Southern blots of IRF-1 (upper panel) and $\beta$-actin (middle panel) RNA transcripts and Western blot of IRF-1 protein (lower panel) in mucosal biopsies taken from treated CD patients cultured in the absence (UNS) or presence of gliadin $(P T)$. Two representative experiments analyzing in total mucosal samples from six patients with treated $\mathrm{CD}$ are shown. (B) Southern blots of IRF-1 (upper panel) and $\beta$-actin (middle panel) RNA transcripts and Western blots of IRF-1 protein (lower panel) in mucosal biopsies taken from normal duodenal biopsies cultured in the absence $(U N S)$ or presence of gliadin $(P T)$ for 8 or $24 \mathrm{~h}$, respectively. Two representative experiments analyzing in total mucosal samples from three normal controls stimulated with gliadin are shown.

up-regulating the expression of vascular cell adhesion molecule-1 $(26,36,37)$. Furthermore, it is well known that IRF-1 can regulate both FasL expression and caspase activity, and promote apoptosis of epithelial cells (38). In this context, it could participate in the complex pattern of events that eventually lead to the villous atrophy. Indeed, recent studies have highlighted the role of FAS-mediated apoptosis in the gliadinmediated induction of mucosal damage (39). Finally, it should be pointed that IRF-1 trans-activating IL-15 could also participate to the development of $\mathrm{CD} 94^{+}$natural killer T cells, which heavily infiltrate the CD mucosa $(18,40,41)$.

In contrast to IRF-1, IRF-2 was expressed at the same level in $\mathrm{CD}$ patients and controls, clearly indicating that these two transcription factors are differently regulated in CD mucosa. Because IRF-2 binds the same DNA sites and therefore competes with IRF-1 (25), it is possible that the increased IRF1:IRF-2 expression ratio may contribute to the sustained IRF1 -binding DNA activity seen in CD.
A

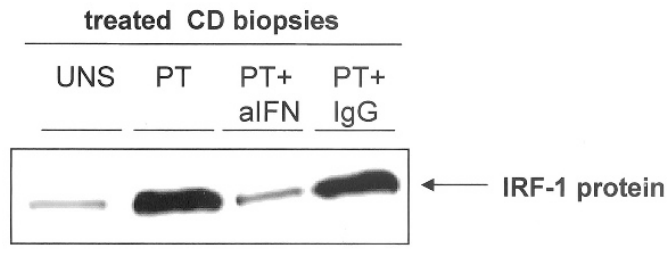

B

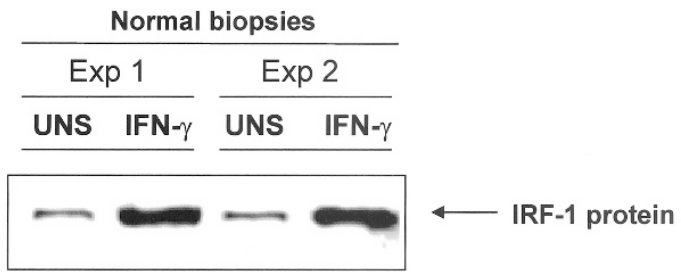

Figure 6. IFN- $\gamma$ induces IRF-1 in the human duodenal mucosa. (A) Stimulation of treated CD biopsies with gliadin enhances IRF-1. This effect is inhibited by a neutralizing IFN- $\gamma$ (aIFN) but not an isotype control antibody (IgG). One of two representative Western blotting experiments analyzing in total mucosal samples from five patients with treated $\mathrm{CD}$ are shown. $(B)$ Western blot of IRF-1 in normal duodenal biopsies cultured in the absence $(U N S)$ or presence of recombinant human IFN- $\gamma$ for $24 \mathrm{~h}$. Two representative experiments analyzing in total mucosal samples from five normal controls are shown.

All the mucosal samples taken from controls contain transcripts for IRF-1, confirming previous studies showing that IRF-1 RNA is expressed at low level in a variety of cell types (42). In addition, IRF-1 protein was found in most of the normal duodenal samples. This is, however, not surprising, given that human intestinal lamina propria is infiltrated with IFN- $\gamma$-secreting cells and with cells containing active STAT1 and NF- $\kappa$ B, the two inducers of IRF-1 $(23,24,28,43)$.

\section{CONCLUSION}

In conclusion, our data indicate that IRF-1 is a hallmark of gliadin-mediated inflammation in $\mathrm{CD}$ and suggest that the IFN- $\gamma /$ IRF-1 signaling pathway may play a role in the maintenance of the Th1 response in CD.

\section{REFERENCES}

1. Schuppan D 2000 Current concept of celiac disease pathogenesis. Gastroenterology 119:234-242

2. Nilsen EM, Jahnsen FL, Lundin KEA, Johansen F-E, Fausa O, Sollid LM, Jahnsen J, Scott H, Brandtzaeg P 1998 Gluten induces an intestinal cytokine response strongly dominated by interferon gamma in patients with celiac disease. Gastroenterology 115:551-563

3. Breese EJ, Kumar P, Farthing MJG, MacDonald TT 1994 Interleukin-2 and interferon-gamma producing cells in the lamina propria in coeliac disease. Dig Dis Sci 39:2243-2248

4. MacDonald TT, Spencer J 1988 Evidence that activated mucosal T cells play a role in the pathogenesis of enteropathy in human small intestine. J Exp Med 167:13411349

5. MacDonald TT, Bajaj-Elliott M, Pender SLF 1999 T cells orchestrate intestinal mucosal shape and integrity. Immunol Today 20:505-510

6. Troncone R, Gianfrani C, Mazzarella G, Greco L, Guardiola J, Auricchio S, De Bernardinis P 1998 Majority of gliadin-specific T-cell clones from celiac small intestinal mucosa produce interferon-gamma and interleukin-4. Dig Dis Sci 43:156161 
7. Reiner SL 2001 Helper T cell differentiation, inside and out. Curr Opin Immunol 13:351-355

8. O'Garra A, Arai N 2000 The molecular basis of T helper 1 and T helper 2 cell differentiation. Trends Cell Biol 10:542-549

9. Monteleone G, Pender SLF, Alstead E, Hauer AC, Lionetti P, MacDonald TT 2001 Role of interferon-alpha in promoting $\mathrm{T}$ helper cell type 1 response in the small intestine in coeliac disease. Gut 48:425-429

10. Monteleone G, Pender SLF, Wathen NC, MacDonald TT 2001 Interferon- $\alpha$ drives T cell-mediated immunopathology in the intestine. Eur J Immunol 31:2247-2255

11. Salvati VM, MacDonald TT, Bajaj-Elliott M, Borrelli M, Staiano A, Auricchio S, Troncone R, Monteleone G 2002 Interleukin-18 and associated markers of T helper cell type 1 activity in celiac disease. Gut 50:186-190

12. Maiuri L, Ciacci C, Auricchio S, Brown V, Quaratino S, Londei M 2000 Interleukin 15 mediates epithelial changes in celiac disease. Gastroenterology 119:996-1006

13. Seder RA 1996 High-dose IL-2 and IL-15 enhance the in vitro priming of naive CD4 $+\mathrm{T}$ cells for IFN-gamma but have differential effects on priming for IL-4. J Immunol 156:2413-2422

14. Sato M, Taniguchi T, Tanaka N 2001 The interferon system and interferon regulatory factor transcription factors - studies from gene knockout mice. Cytokine Growth Factor Rev 12:133-142

15. Miyamoto M, Fujita T, Kimura Y, Maruyama M, Harada H, Sudo Y, Miyata T, Taniguchi T 1988 Regulated expression of a gene encoding a nuclear factor, IRF-1, that specifically binds to IFN- $\gamma$ gene regulatory elements. Cell 54:903-913

16. Fujita T, Kimura Y, Miyamoto M, Barsoumian EL, Taniguchi T 1989 Induction of endogenous IFN- $\alpha$ and IFN- $\beta$ genes by a regulatory transcription factor, IRF-1. Nature 337:270-272

17. Fantuzzi G, Reed DA, Qi M, Scully S, Dinarello CA, Senaldi G 2001 Role of interferon regulatory factor-1 in the regulation of IL-18 production and activity. Eur J Immunol 31:369-375

18. Ohteki T, Yoshida H, Matsuyama T, Duncan GS, Mak TW, Ohashi PS1998 The transcription factor interferon regulatory factor 1 (IRF-1) is important during the maturation of natural killer $1.1^{+} \mathrm{T}$ cell receptor- $\alpha / \beta^{+}\left(\mathrm{NK}{ }^{+} \mathrm{T}\right)$ cells, natural killer cells, and intestinal intraepithelial T cells. J Exp Med 16:967-972

19. Taki S, Sato T, Ogasawara K, Fukuda T, Sato M, Hida S, Suzuki G, Mitsuyama M, Shin EH, Kojima S, Taniguchi T, Asano Y 1997 Multistage regulation of Th1-type immune responses by the transcription factor IRF-1. Immunity 6:673-679

20. Fais S, Maiuri L, Pallone F, De Vincenzi M, De Ritis G, Troncone R, Auricchio S 1992 Gliadin induced changes in the expression of MHC-class II a by human small intestinal epithelium. Organ culture studies celiac disease mucosa. Gut 33:472-475

21. Monteleone G, Biancone L, Marasco R, Morrone G, Marasco O, Luzza F, Pallone F 1997 Interleukin 12 is expressed and actively released by Crohn's disease intestinal lamina propria mononuclear cells. Gastroenterology 112:1169-1178

22. Reinecker HC, MacDermott RP, Mirau S, Dignass A, Podolsky DK 1996 Intestina epithelial cells both express and respond to interleukin 15. Gastroenterology 111:1706-1713

23. Schreiber S, Nikolaus S, Hampe J 1998 Activation of nuclear factor $\kappa$ B in inflammatory bowel disease. Gut 42:477-484

24. Monteleone G, Trapasso F, Parrello T, Biancone L, Stella A, Iuliano R, Luzza F, Fusco A, Pallone F 1999 Bioactive interleukin-18 expression is up-regulated in Crohn's disease. J Immunol 163:143-147

25. Harada H, Fujita T, Miyamoto M, Kimura Y, Maruyama M, Furia A, Miyata T, Taniguchi T 1989 Structurally similar but functionally distinct factors, IRF-1 and IRF-2, bind to the same regulatory elements of IFN and IFN-inducible genes. Cell 58:729-739

26. Taniguchi T, Ogasawara K, Takaoka A, Tanaka N2001 IRF family of transcription factors as regulators of host defence. Annu Rev Immunol 19:623-655
27. Forsberg G, Hernell O, Melgar S, Israelsson A, Hammarstrom S, Hammarstrom M-L 2002 Paradoxical coexpression of proinflammatory and down-regulatory cytokines in intestinal T cells in childhood celiac disease. Gastroenterology 123:667-678

28. MacDonald TT 1998 T cell immunity to oral allergens. Curr Opin Immunol 10:620 627

29. Nagata S, McKenzie C, Pender SLF, Bajaj-Elliott M, Fairclough PD, Walker-Smith JA, Monteleone G, MacDonald TT 2000 Human Peyer' s patch T cells are sensitized to dietary antigen and display a $\mathrm{T}$ helper cell type 1 cytokine profile. J Immunol $165: 5315-5321$

30. MacDonald TT, Monteleone G 2001 IL-12 and Th1 immune responses in human Peyer's patches. Trends Immunol 22:244-247

31. McElligott DL, Phillips JA, Stillman CA, Koch RJ, Mosier DE, Hobbs MV 1997 CD4+ T cells from IRF-1-deficient mice exhibit altered patterns of cytokine expression and cell subset homeostasis. J Immunol 159:4180-4186

32. Suk K, Kim S, Kim YH, Kim KA, Chang I, Yagita H, Shong M, Lee MS 2001 IFN-gamma/TNF-alpha synergism as the final effector in autoimmune diabetes: a key role for STAT1/IFN regulatory factor-1 pathway in pancreatic beta cell death. J Immunol 166:4481-4489

33. Nakazawa T, Satoh J, Takahashi K, Sakata Y, Ikehata F, Takizawa Y, Bando SI, Housai T, Li Y, Chen C, Masuda T, Kure S, Kato I, Takasawa S, Taniguchi T, Okamoto H, Toyota T 2001 Complete suppression of insulitis and diabetes in NOD mice lacking interferon regulatory factor-1. J Autoimmun 17:119-125

34. Tada Y, Ho A, Matsuyama T, Mak TW 1997 Reduced incidence and severity of antigen-induced autoimmune disease in mice lacking interferon regulatory factor-1. J Exp Med 185:231-238

35. Sommer F, Faller G, Rollinghoff M, Kirchner T, Mak TW, Lohoff M 2001 Lack of gastritis and of an adaptive immune response in interferon regulatory factor-1deficient mice infected with Helicobacter pylori. Eur J Immunol 31:396-402

36. Kamijo R, Harada H, Matsuyama T, Bosland M, Gerecitano J, Shapiro D, Le J, Koh SI, Kimura T, Green SJ 1994 Requirement for transcription factor IRF-1 in NO synthase induction in macrophages. Science 263:1612-1615

37. Kimura T, Kadokawa Y, Harada H, Matsumoto M, Sato M, Kashiwazaki Y, Tarutan M, Tan RS, Takasugi T, Matsuyama T, Mak TW, Noguchi S, Taniguchi T 1996 Essential and non-redundant roles of p48 (ISGF3 gamma) and IRF-1 in both type I and type II interferon responses, as revealed by gene targeting studies. Genes Cells $1: 115-124$

38. Chow WA, Fang JJ, Yee J-K 2000 The IFN regulatory factor family participates in regulation of FAS ligand gene expression in T cells. J Immunol 164:3512-3518

39. Maiuri L, Ciacci C, Raia V, Vacca L, Ricciardelli I, Raimondi F, Auricchio S, Quaratino S, Londei M 2001FAS engagement drives apoptosis of enterocytes of coeliac patients. Gut 48:418-424

40. Maiuri L, Ciacci C, Vacca L, Ricciardelli I, Auricchio S, Quaratino S, Londei M 2001 IL-15 drives the specific migration of CD94+ and TCR-gammadelta + intraepithelial lymphocytes in organ cultures of treated celiac patients. Am J Gastroenterol 96:150156

41. Jabri B, de Serre NP, Cellier C, Evans K, Gache C, Carvalho C, Mougenot JF, Allez M, Jian R, Desreumaux P, Colombel JF, Matuchansky C, Cugnenc H, Lopez-Botet M, Vivier E, Moretta A, Roberts AI, Ebert EC, Guy-Grand D, Brousse N, Schmitz J, Cerf-Bensussan N 2000 Selective expansion of intraepithelial lymphocytes expressing the HLA-E-specific natural killer receptor CD94 in celiac disease. Gastroenterology 118:867-879

42. Tanaka N, Taniguchi $\mathrm{T} 2000$ The interferon regulatory factors and oncogenesis. Semin Cancer Biol 10:73-81

43. Kuhbacher T, Gionchetti P, Hampe J, Helwig U, Rosenstiel P, Campieri M, Buhr HJ, Schreiber S 2001 Activation of signal-transducer and activator of transcription 1 (STAT1) in pouchitis. Clin Exp Immunol 123:395-401 